\title{
Primary Breakup of Round Turbulent Liquid Jets in Uniform Crossflows
}

\author{
C. Aalburg ${ }^{*}$ \\ G.E. Global Research, Munich, Germany
}

G.M. Faeth ${ }^{\dagger}$

The University of Michigan, Ann Arbor, MI 48109-2140

and

K.A. Sallam

Oklahoma State University, Stillwater, OK

\begin{abstract}
An experimental investigation of the deformation and breakup properties of turbulent round liquid jets in uniform gaseous crossflows is described. Pulsed shadowgraph and holograph observations were obtained for turbulent round liquid jets injected normal to an air crossflow in a shock tube. Crossflow velocities of air behind the shock wave relative to the liquid jet were subsonic (11-142 $\mathrm{m} / \mathrm{s})$, with the air in this region at normal temperature and pressure. Liquid injection was done by a pressure feed system through round tubes having inside diameters of 1 and $2 \mathrm{~mm}$ and length-to-diameter ratios greater than 100 to provide fully-developed turbulent pipe flow at the jet exit. Test conditions were as follows: water and ethyl alcohol as test liquids, crossflow Weber numbers based on gas properties of 0-282, streamwise Weber numbers based on liquid properties of 5,100-24,500, liquid/gas density ratios of 683 and 845 , and jet exit Reynolds numbers based on liquid properties of 3,800-59,000, all at conditions where direct effects of liquid viscosity were small (Ohnesorge numbers were less than 0.12 ). Measurements were completed to determine breakup regime transitions, conditions required for the onset of breakup. ligament and drop sizes along the liquid surface, drop velocities after breakup, and rates of turbulent primary breakup. Phenomenological theories proved to be quite successful in helping to interpret and correlate the measurements, providing information needed to define initial conditions for typical numerical simulations of spray structure.
\end{abstract}

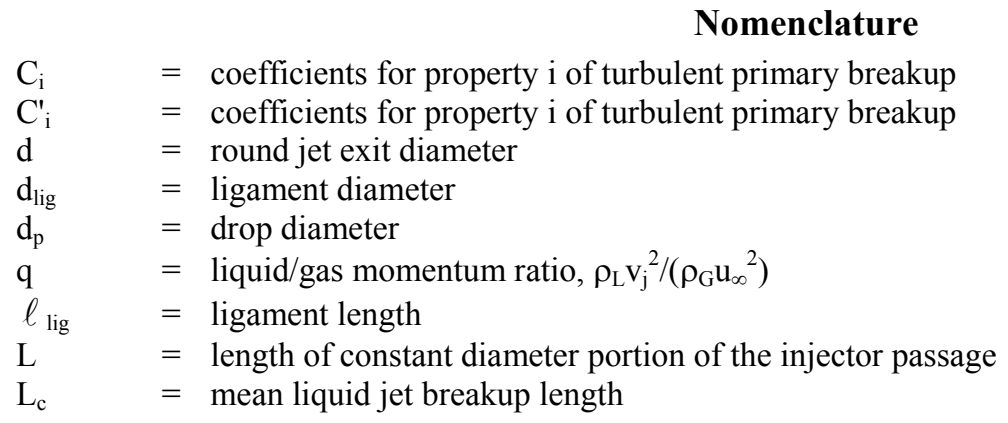

\footnotetext{
* Research Engineer.

'Professor, Department of Aerospace Engineering, Fellow AIAA, Corresponding author, Tel: +1-734-764-7202; Fax: +1-734-936-0106; E-mail: gmfaeth@umich.edu (G.M. Faeth).

Assistant Professor, Department of Aerospace Engineering.
} 


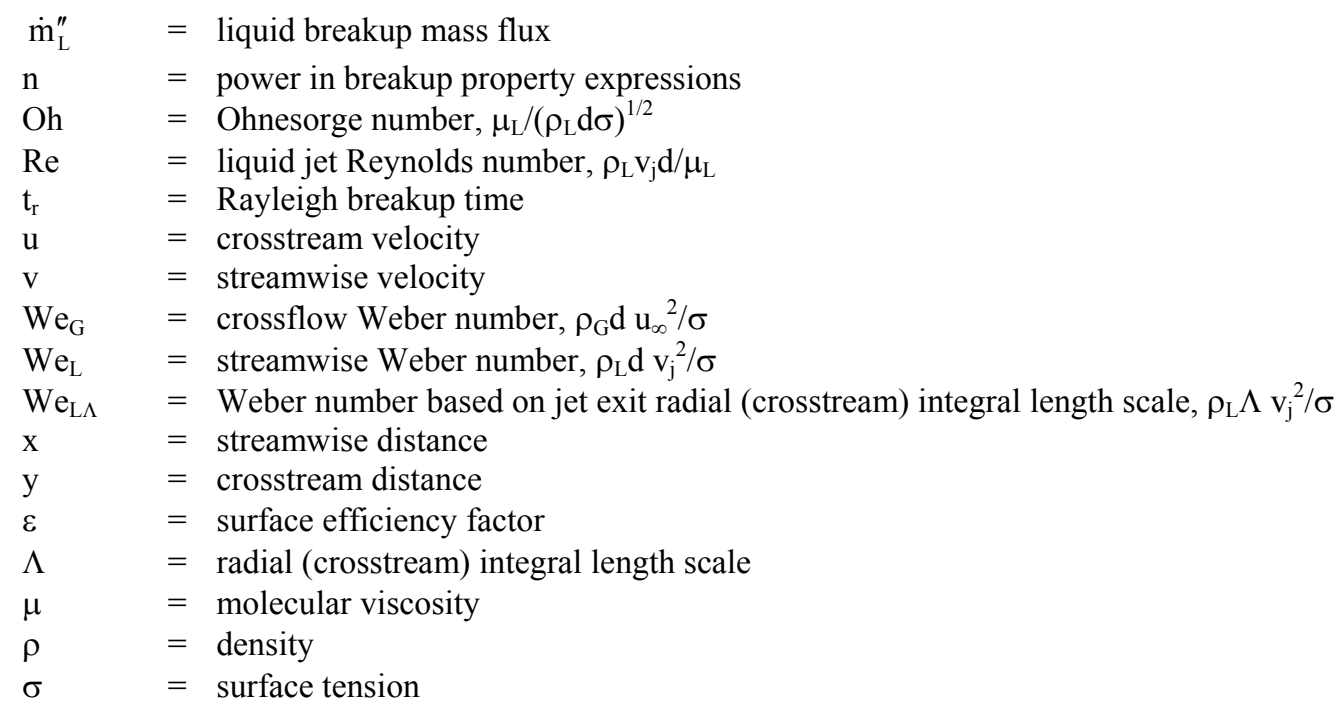

\section{Subscripts}

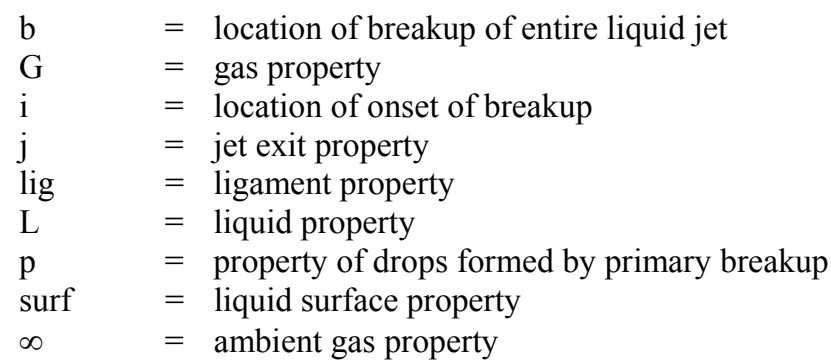

Superscripts

$$
\begin{array}{ll}
\left({ }^{-}\right) & =\text {mean property of turbulence } \\
\left({ }^{\prime}\right)^{\prime} & =\text { rms fluctuating property of turbulence }
\end{array}
$$

\section{INTRODUCTION}

R ECENT experimental and computational studies due to Mazallon et al., ${ }^{1}$ Sallam et al. ${ }^{2}$ and Aalburg et al. ${ }^{3}$ considered the deformation and breakup properties of nonturbulent round liquid jets in uniform gaseous crossflows. This research was motivated by applications to the primary breakup of liquid jets in crossflow encountered in air-breathing propulsion systems, liquid rocket engines, diesel engines, spark ignition engines and agricultural sprays, among others. The objective of the present investigation was to extend these results to consider primary breakup of turbulent liquid jets in uniform gaseous crossflows because most practical sprays involve some level of turbulent disturbance in the liquid jet leaving the injector exit.

In order to control the scope of the present study, however, jet exit turbulence was at the well-defined limit of fully-developed turbulent pipe flow which is representative of high Reynolds number injector flows for large length/diameter ratio injectors. Given results for liquid jet exit conditions at the limits of nonturbulent and fullydeveloped turbulent pipe flow, it was felt that partial degrees of turbulence development in the liquid could be more systematically addressed during subsequent studies.

Early studies of primary breakup of round nonturbulent liquid jets in uniform gaseous crossflows have been recently reviewed by Aalburg et al. ${ }^{3}$ and references cited therein; therefore, the present review of this literature will be limited to recent studies. Mazallon et al., ${ }^{1}$ and Sallam et al. ${ }^{2}$ considered breakup involving large liquid/gas density ratios based on experiments using pulsed shadowgraph and holograph observations of primary breakup regimes, considerations required for the onset of ligament and drop formation, ligament and drop sizes along the liquid 
surface, drop velocities after breakup, rates of liquid breakup between the onset of drop formation and breakup of the liquid column as a whole, conditions required for the breakup of the liquid column as a whole, and liquid column trajectories - all for subsonic air crossflows at normal temperature and pressure (NTP). The results suggested qualitative similarities between the primary breakup of nonturbulent round liquid jets in gaseous crossflow and the secondary breakup of drops subjected to shock wave disturbances. It was also found that phenomenological analyses were effective to help interpret and correlate the measurements. This research was extended by the computational and experimental study of the deformation and breakup properties of nonturbulent round liquid jets in uniform gaseous crossflows due to Aalburg et al. ${ }^{3}$ that sought to use computations to study aspects of breakup that are difficult to address by experiments. The main results were that there were relatively small effects of liquid/gas density and viscosity ratios on deformation and breakup regime boundaries and that there was a significant increase of the resistance of liquid jets in crossflow to deformation when small crossflow Reynolds number conditions, approaching the Stokes flow regime, were approached. A major limitation of these studies, however, was that effects of liquid turbulence on the deformation and breakup properties of round liquid jets in crossflow were not investigated; this is unfortunate, because most practical liquid injectors introduce some degree of turbulence in the liquid jet leaving the injector passage.

Drop formation along the surface of turbulent liquids, called turbulent primary breakup, is a common mechanism of spray formation in industrial and natural processes, e.g., spray atomization, bow waves of ships, whitecaps, etc. The turbulent primary breakup mechanism was first identified by De Juhasz et al. ${ }^{4}$ and Lee and Spenser. ${ }^{5,6}$ Subsequent studies due to Schweitzer, ${ }^{7}$ Chen and Davis, ${ }^{8}$ Grant and Middleman, ${ }^{9}$ Phinney, ${ }^{10}$ McCarthy and Malloy, ${ }^{11}$ and Hoyt and Taylor ${ }^{12,13}$ confirmed that liquid turbulence affected spray properties, and that turbulent primary breakup dominated the formation of ligaments and drops near the surface of turbulent liquids in still or slowly moving gases at NTP.

Subsequent studies due to Wu et al., ${ }^{14-17}$ Dai et al., ${ }^{18}$ and Sallam and coworkers ${ }^{19-21}$ used pulsed shadowgraphy and holography to study the properties of turbulent primary breakup for fully-developed liquid turbulence for a variety of turbulent liquid geometries in still gases. The main findings were as follows: aerodynamic effects were small for liquid/gas density ratios greater than 500; drop size distributions after turbulent primary breakup satisfied the universal root normal distribution of Simmons ${ }^{22}$ and were completely defined by the Sauter mean diameter (SMD) of the sprays; drop velocities after breakup were independent of drop size and were simply related to the mean and rms fluctuating velocities of the turbulent liquid at the jet exit; and the SMD, ligament properties, drop properties and rate of liquid breakup along the liquid surface could be interpreted and correlated based on simplified phenomenological analyses. Unfortunately, none of these studies involved consideration of gas flows across the turbulent liquid surface sufficient to introduce significant aerodynamic effects.

The objective of the present investigation was to extend the studies of liquid breakup for nonturbulent round liquid jets in crossflow, ${ }^{1-3}$ and for turbulent primary breakup of liquids in the presence of negligible aerodynamic effects, ${ }^{4-21}$ to consider the breakup properties of turbulent round liquid jets in uniform crossflows, using similar experimental methods to the past work. In order to control the scope of the research, however, breakup was considered in uniform air crossflows at NTP with the liquid turbulence limited to fully-developed turbulent pipe flow at the injector exit. Finally, similar to past work, ${ }^{1-21}$ phenomenological analyses were used to help interpret and correlate the measurements.

The following description of the research begins with consideration of experimental methods. Results are then discussed considering breakup regimes, liquid surface velocities, conditions for the onset of liquid breakup along the liquid jet surface, the variation of ligament and drop sizes along the liquid surface, the variation of drop velocities along the liquid surface, and the variation of the rate of liquid breakup along the liquid surface.

\section{EXPERIMENTAL METHODS}

\section{$\underline{\text { Apparatus }}$}

Observations of liquid breakup along the surface of a round liquid jet were carried out using a shock tube apparatus as sketched in Fig. 1. The shock tube had a rectangular cross section with a width of $38 \mathrm{~mm}$ and a height of $64 \mathrm{~mm}$. The driven section of the shock tube was open to the atmosphere and had windowed side walls to provide optical access. The shock tube was sized to provide test times of 17-20 ms in the uniform subsonic flow region behind the shock wave. Crossflow velocities of $11-142 \mathrm{~m} / \mathrm{s}$ in air at NTP were considered. 
Pressure injection was used to feed the test liquids from a cylindrical storage chamber into round nozzles directed vertically downward across the mid-plane of the shock tube. The injector system for fully-developed turbulent liquid round liquid jets in uniform gaseous crossflows is sketched in Fig. 1. The storage chamber had an inside diameter and length of 50 and $100 \mathrm{~mm}$, respectively. The nozzles had smooth rounded entrances with length-to-diameter ratios greater than 100:1 to help insure fully-developed turbulent pipe flow at the jet exit for sufficiently large liquid jet Reynolds numbers, as discussed by $\mathrm{Wu}$ et al. ${ }^{16}$ and references cited therein.

The test liquid was placed in the storage chamber through a port with premature outflow prevented by surface tension forces at the injector exit. The liquid was forced through the nozzle by admitting highpressure air to the top of the chamber through a solenoid valve. The high-pressure air was stored in an accumulator having a volume of $1.3 \mathrm{cu}-\mathrm{m}$ on the upstream side of the solenoid valve, with provision for accumulator air pressures up to $1.5 \mathrm{MPa}$ (with air dewpoints smaller than $240 \mathrm{~K}$ ). Significant aeration of the test liquid was prevented in several ways: a baffle was placed across the air inlet of the liquid supply chamber, the cross sectioned area of the supply chamber was large compared to the injector tube cross sectional area (streamwise liquid velocities in the chamber were less than $70 \mathrm{~mm} / \mathrm{s}$ ), and liquid during present observations was drawn from the bottom of the liquid supply chamber well away from the liquid surface. Notably, these steps were sufficient to prevent observation of bubbles in the liquid for the observations of nonturbulent liquid jets of Sallam et al. ${ }^{2}$ Once all the liquid was forced out of the liquid supply chamber, the solenoid valve was closed and the liquid supply chamber was refilled for the next test.

Test times were short for the shock tube arrangement, less than $20 \mathrm{~ms}$, however, this was not a problem because flow development times (the time required for a given liquid sample to cross the flow cross section) were smaller than $1 / 3$ of available test times. In addition, data acquisition times, using pulsed shadowgraphy and holography, were even shorter, less than $10 \mathrm{~ns}$, and did not impose any significant test time requirements.

The uniformity of the crossflow acting on the round liquid jets is an important issue discussed by Mazallon et al. ${ }^{1} \quad$ For present results, measurements were obtained at short times (less than $20 \mathrm{~ms}$ ) after passage of the shock wave past the liquid jet locator. As a result, the thickness of the nonuniform velocity field in the boundary layer along the shock tube walls was generally less than $0.5 \mathrm{~mm}$, based on the transient analysis presented by Schlichting. ${ }^{23}$ In addition, the injector tube was shifted normal to the wall in order to observe the flow at various positions along the liquid jet; as a result, the disturbed region along the wall was smaller than $10 \%$ of the distance along the liquid jet for all observations made during the present investigation.

\section{Instrumentation}

Pulsed shadowgraphy and holography were used for all observations of the liquid surface and its breakup properties during the present investigation. The instruments and data processing methods were identical to past work, Sallam et al. ${ }^{2,19,20}$ should be consulted for the details.

Ligament properties were found similar to Sallam et al. ${ }^{20}$ whereas drop properties after primary breakup were found similar to Sallam et al. ${ }^{2,19}$ Ligaments were approximately cylindrical and could be represented by their average diameters and lengths. Drops generally were spherical and could be completely described by the SMD under the approximations of the universal root normal drop size distribution function of Simmons. ${ }^{22}$ Experimental uncertainties (95\% confidence) were found using standard methods similar to past work. ${ }^{2,19,20}$ These uncertainties were less than $10 \%$ for ligament and drop diameters larger than $10000 \mathrm{~nm}$, increasing inversely proportional to the diameter for smaller sized objects. Drop velocities were found from simple arithmetic averages (because drop velocity distributions as a function of size were nearly uniform) with experimental uncertainties (95\% confidence) less than $10 \%$. In all cases, the numbers of drops or ligaments measured at a point were chosen to achieve the experimental uncertainties just mentioned. 


\section{$\underline{\text { Test Conditions }}$}

Test conditions are summarized in Table 1. Liquid properties appearing in Table 1 were measured as follows: liquid densities using a set of precision hygrometers (Fisher Model 11-582, 0.1\% accuracy), liquid viscosities using a CannonFenske viscometer (Fisher Model 13-617, 3\% accuracy), and surface tensions using a ring tensiometer (Fisher Model 10, 1\% accuracy). The present results agreed with values appearing in Lange ${ }^{24}$ within the accuracy of the instruments.

Test conditions were varied by considering two different liquids (water and ethyl alcohol), injector passage diameters of 1.0 and $2.0 \mathrm{~mm}$, liquid jet velocities of $7-45 \mathrm{~m} / \mathrm{s}$ and air crossflow velocities of $11-142 \mathrm{~m} / \mathrm{s}$ at NTP. This yielded the following ranges of test variables: liquid/gas density ratios of 683 and 845 , liquid jet Reynolds numbers, Re, of 3800 59000; crossflow Weber numbers, $\mathrm{We}_{\mathrm{G}}$, of 0 282, streamwise Weber numbers, $\mathrm{We}_{\mathrm{L}}$, of 5500-24500, and liquid jet Ohnesorge numbers, Oh, of 0.003-0.120. Crossflow Mach numbers were smaller than 0.1 ; therefore, compressivity effects were negligible.

Table 1 Summary of Test Conditions ${ }^{\mathrm{a}}$

\begin{tabular}{|c|c|c|}
\hline Liquid & Water & Ethyl Alcohol \\
\hline Density, $\mathrm{kg} / \mathrm{m}^{3}$ & 995 & 806 \\
\hline Liquid/gas density ratio, $\rho_{\mathrm{L}} / \rho_{\mathrm{G}}$ & 845 & 683 \\
\hline Liquid viscosity, $\mathrm{kg} / \mathrm{m}-\mathrm{s} \times 10^{4}$ & 8.94 & 12.3 \\
\hline Liquid/gas viscosity ratio, $\mu_{\mathrm{L}} / \mu_{\mathrm{G}}$ & 48 & 66 \\
\hline Surface tension, $\mathrm{N} / \mathrm{m} \times 10^{3}$ & 70.8 & 24.0 \\
\hline Injector exit passage diameter, $\mathrm{mm}^{\mathrm{b}}$ & $1.0,2.0$ & $1.0,2.0$ \\
\hline Liquid jet Reynolds number, Re & $3,800-59,000$ & $8,000-32,000$ \\
\hline Crossflow Weber number. $\mathrm{We}_{\mathrm{G}}$ & $0-159$ & $0-282$ \\
\hline Streamwise Weber number, $\mathrm{We}_{\mathrm{L}}$ & $5,100-11,000$ & $14,600-24,500$ \\
\hline Liquid/gas momentum ratio, $\mathrm{q}$ & $3-200$ & $20-100$ \\
\hline Liquid jet Ohnesorge number, $\mathrm{Oh} \times 10$ & $3-4$ & $80-120$ \\
\hline
\end{tabular}

\section{RESULTS AND DISCUSSION}

\section{Flow Visualization}

Injector passage design, including the inlet contraction, the presence of trips and other turbulence-promoting devices, and the roughness and length of the constant-diameter portion of the injector passage, can all modify conditions required for turbulent flow (and its degree of development) at the jet exit. ${ }^{15,23}$ Naturally, these variables also control the nature of the turbulence at the injector exit. Thus, in order to control the number of test variables, the present experiments were limited to relatively long injector passages, $\mathrm{L} / \mathrm{d}>100$, in order to achieve fullydeveloped turbulent pipe flows for sufficiently large jet exit Reynolds numbers as discussed by Wu et al. ${ }^{16}$

Visualization of the flow at the injector exit is provided by the pulsed photographs of the flow near the jet exit illustrated in Fig. 2. Three jet exit conditions are shown: contraction-section boundary-layer removal using a cutter followed by a short constant diameter section having $\mathrm{L} / \mathrm{d}=0.5$; contraction-section boundarylayer removal using a cutter followed by a constant diameter section having $\mathrm{L} / \mathrm{d}=4.0$; and a round contraction followed by a long constant diameter section having $\mathrm{L} / \mathrm{d}=10.0$ (the last having the same general configuration as the present injectors but with a shorter $\mathrm{L} / \mathrm{d}$ of the constant diameter section, 10 as opposed to greater than 100). All three flows involve $\operatorname{Re}=260,000$, which is sufficient to obtain fullydeveloped turbulent pipe flow for sufficiently long L/d. ${ }^{16,23}$

In fact, normal turbulent primary breakup, with an irregular liquid surface near the jet exit followed by the

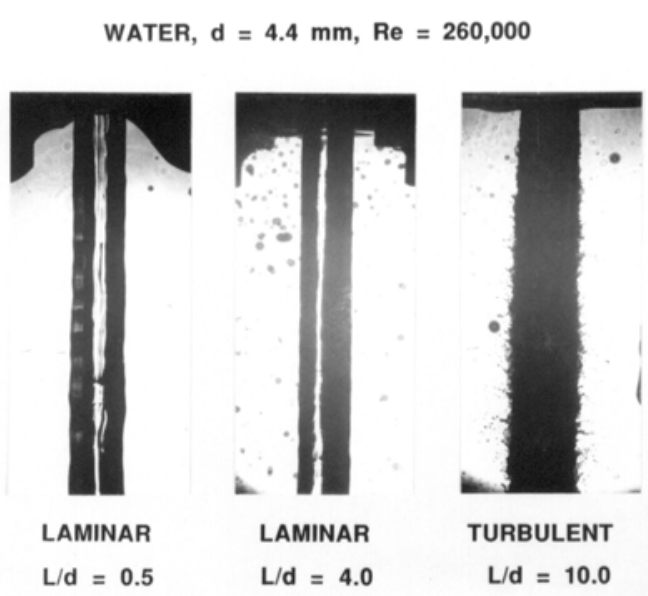

Figure 2. Pulsed shadowgraphs of nonturbulent and turbulent round liquid jets in still gases near the injector exit (test conditions: water jets in air with $\operatorname{Re}=\mathbf{2 6 0 , 0 0 0 )}$. 
formation of irregular ligaments and drops farther downstream, is observed for $\mathrm{L} / \mathrm{d}=10.0$, which corresponds to conditions with somewhat smaller $\mathrm{L} / \mathrm{d}$ than the present study considered by $\mathrm{Wu}$ and coworkers ${ }^{14-17}$ and Sallam and coworkers $^{19-21}$ during earlier studies of turbulent primary breakup. On the other hand, the liquid surface remains smooth near the jet exit, with no breakup observed and jet properties approximating the behavior of a liquid cutting jet, for $\mathrm{L} / \mathrm{d}=0.5$ and 4.0. Increasing the length of the constant diameter section to $\mathrm{L} / \mathrm{d}=10$, however, yields a turbulent primary breakup process very similar to observations with large $\mathrm{L} / \mathrm{d}$ passages. Thus, present test conditions with $\mathrm{L} / \mathrm{d}$ greater than 100 seem reasonably assured of reaching fully-developed turbulent pipe flow conditions at the jet exit.

\section{Mean Liquid Column Breakup Lengths in Still Gases}

In order to define general conditions for turbulent primary breakup, and to baseline present measurements, the earlier turbulent primary breakup measurements of $\mathrm{Wu}$ and Faeth $^{17}$ were used. These results all were for turbulent primary breakup in still air at NTP. The combined measurements are plotted in Fig. 3. Results shown on the plot pertain to three turbulent primary breakup conditions along the liquid surface, as follows: the breakup of the entire liquid column due to the turbulent primary breakup mechanism, $\mathrm{L}_{\mathrm{c}} / \mathrm{d}$; the onset of turbulent primary breakup along the liquid surface, $\mathrm{x}_{\mathrm{i}} / \mathrm{d}$; and the end of turbulent primary breakup along the liquid surface, $x_{e} / d$. The criterion for the liquid column length for turbulent primary breakup is given by $\mathrm{Wu}$ and Faeth ${ }^{17}$ as follows:

$$
\mathrm{L}_{\mathrm{c}} / \mathrm{d}=8.51 \mathrm{We}_{\mathrm{L}}^{0.32}
$$

The functional forms of the correlations for $\mathrm{x}_{\mathrm{i}} / \mathrm{d}$ and $\mathrm{x}_{\mathrm{e}} / \mathrm{d}$ are also similar to Eq. (1), see $\mathrm{Wu}$ and Faeth ${ }^{17}$ for the specific correlations for each regime. Present measurements were limited to the onset of turbulent

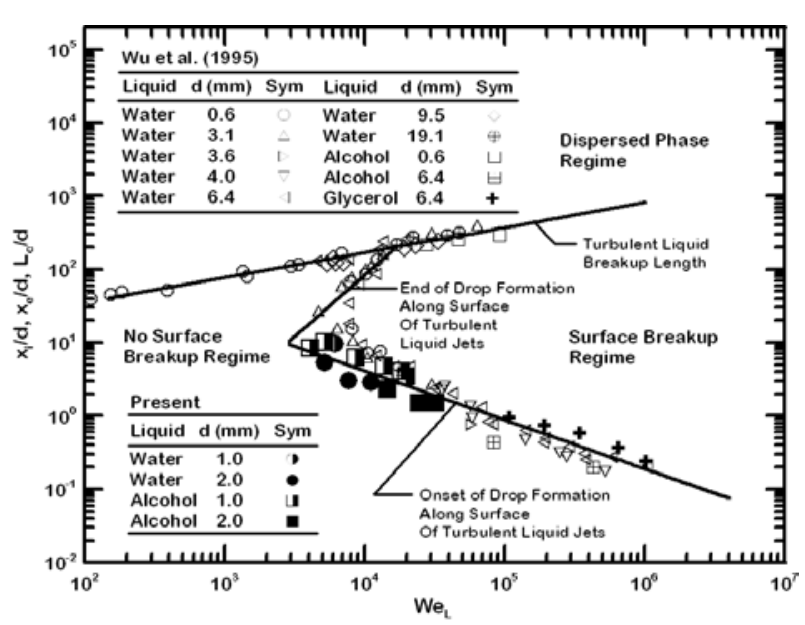

Figure 3. Mean liquid column breakup lengths of turbulent round liquid jets in still air, plotted according to the turbulent liquid column breakup analysis of Sallam et al. $^{20}$ and the onset and end of liquid surface breakup analyses of $\mathrm{Wu}$ and Faeth. ${ }^{15}$ primary breakup along the liquid surface and are seen to be in excellent agreement with the earlier measurements of $\mathrm{Wu}$ and Faeth ${ }^{17}$ for this condition. Finally, there are two other regimes for the length of the liquid column: Rayleigh-type breakup and bag/shear breakup of the liquid column. The present shock tube apparatus, however, was too confined to allow observation of liquid column breakup lengths in the absence of crossflow; see Sallam et al. ${ }^{20}$ for a discussion of these liquid column breakup properties.

\section{Mean Liquid Surface Streamwise Velocities}

In order to characterize turbulent primary breakup properties along the liquid surface, it is useful to consider the variation of streamwise liquid surface velocities as a function of distance from the injector exit. These measurements were carried out with no crossflow present; the results are illustrated in Fig. 4. Measured velocities shown in the figure are timeaveraged streamwise liquid surface velocities normalized by the jet exit mean velocity, $\overline{\mathrm{v}}_{\text {surf }} / \overline{\mathrm{v}}_{\mathrm{j}}$. It was found that $\bar{v}_{\text {surf }} / \bar{v}_{j}$ is essentially independent of the liquid jet; or

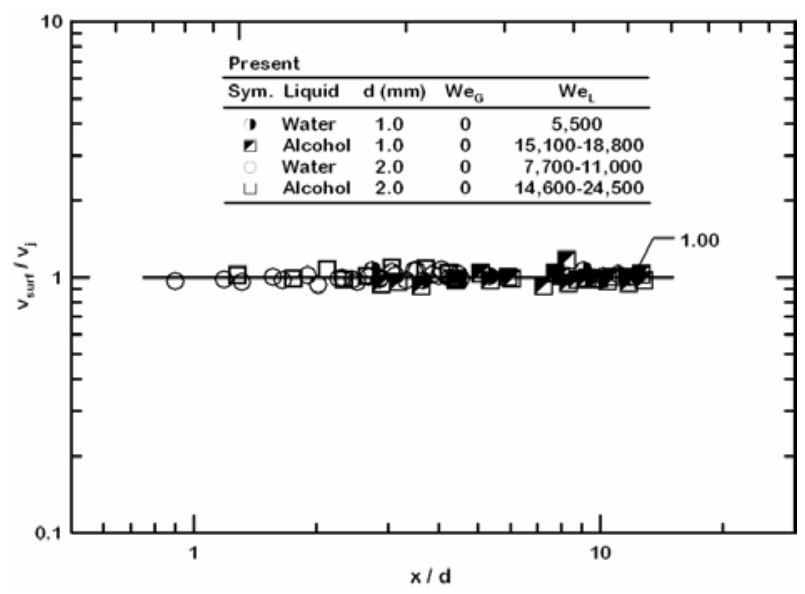

Figure 4. Mean liquid surface velocities as a function of distance from the jet exit.

6 


$$
\overline{\mathrm{v}}_{\text {surf }} / \overline{\mathrm{v}}_{\mathrm{j}}=1.0
$$

Thus, the streamwise liquid surface velocity is essentially equal to mean streamwise jet velocity at the jet exit, which is behavior essentially identical to the behavior of nonturbulent round liquid jets in gaseous crossflows from Sallam et al. $^{2}$ Noting that this result was independent of crossflow velocities for nonturbulent round liquid jets having similar cross stream momentum fluxes, it is anticipated that the surface velocities of the present round turbulent liquid jets will similarly be relatively independent of cross stream velocities.

\section{Onset of Turbulent Primary Breakup}

Consideration of conditions at the onset of turbulent primary breakup along the liquid surface, allowing for aerodynamic-enhancement of the breakup process, followed the earlier phenomenological analyses of $\mathrm{Wu}$ and Faeth. ${ }^{15}$ Enhanced aerodynamic primary breakup was associated with effects of pressure drops caused by the acceleration of the surrounding gas over protrusions (ligaments) from the liquid surface. The analysis involved extending the approach of Wu et al., ${ }^{14}$ where the onset of breakup was determined by conditions where the momentum of turbulent fluctuations in the liquid was just sufficient to overcome surface tension forces so that ligaments can form, to include aerodynamic contributions to the formation of ligaments, and thus drops. Then the location of the onset of breakup follows from the time required for a ligament to grow and produce a drop at its tip due to Rayleigh breakup. The breakup time is converted to a length along the liquid surface based on the assumption

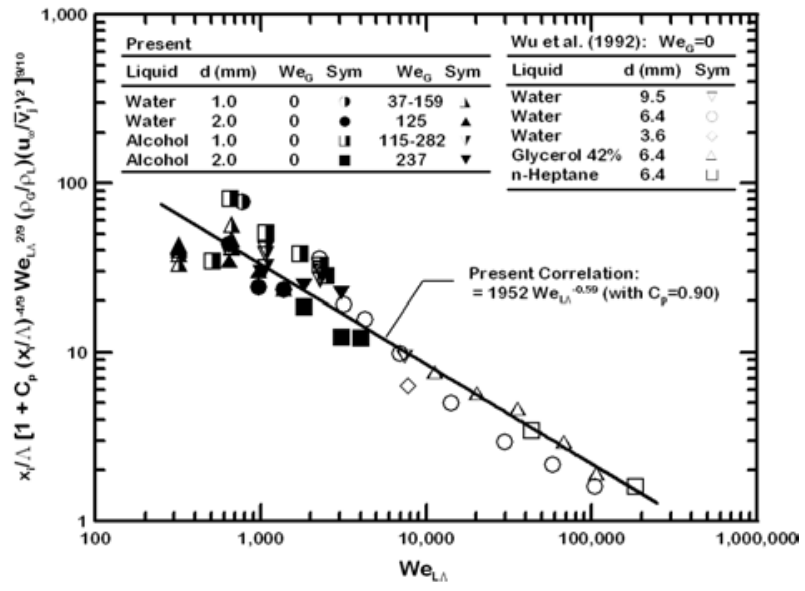

Figure 5. Streamwise length to onset of breakup as a function of Weber number for turbulent liquid jets in crossflow. that ligaments convect along the liquid surface in the streamwise direction at $\overline{\mathrm{v}}_{\text {surf }}=\overline{\mathrm{v}}_{\mathrm{j}}$, which is justified by the results illustrated in Fig. 4. This phenomenological analysis follows $\mathrm{Wu}$ and Faeth ${ }^{15}$ and yields the following result for the aerodynamically-enhanced streamwise location for the onset of turbulent primary breakup along the liquid surface:

$$
\left(\mathrm{x}_{\mathrm{i}} / \Lambda\right)\left[1+\mathrm{C}_{\mathrm{p}}\left(\mathrm{x}_{\mathrm{i}} / \Lambda\right)^{-4 / 9} \mathrm{We}_{\mathrm{L} \Lambda}^{2 / 9}\left(\rho_{\mathrm{G}} / \rho_{\mathrm{L}}\right)\left(\mathrm{u}_{\infty} / \overline{\mathrm{v}}_{\mathrm{j}}^{\prime}\right)^{2}\right]^{9 / 10}=\mathrm{C}_{\mathrm{xi}} \mathrm{We}_{\mathrm{L} \Lambda}^{-\mathrm{n}}
$$

where $n=4 / 10$.

The present measurements with and without crossflow, are plotted according to Eq. (3) in Fig. 5. Also included are the measurements of $\mathrm{Wu}$ et al. ${ }^{19}$ for no crossflow. In completing this plot, the values, $\mathrm{C}_{\mathrm{p}}=0.90, \mathrm{C}_{\mathrm{xi}}=1952$ and $\mathrm{n}=0.59$ have been selected as best-fit values to achieve a correlation between $\mathrm{x}_{\mathrm{i}} / \Lambda$ and the other properties of the breakup process. This selection depends on taking $\overline{\mathrm{v}}_{\mathrm{j}}^{\prime} / \overline{\mathrm{v}}_{\mathrm{j}}=0.03$ for the bulk liquid for fully-developed turbulent pipe flow from $\mathrm{Hinz}^{25}$ ). The difference between the theoretical value of $\mathrm{n}=0.40$ and the correlated value of 0.59 is statistically significant but is not large in view of the approximations used to develop the correlating expression (notably, Wu and Faeth ${ }^{15}$ find $\mathrm{n}=0.63$ for these measurements, very close to the present value). The large value $\mathrm{C}_{\mathrm{xi}}$ can be anticipated because: ${ }^{15}$

$$
\mathrm{C}_{\mathrm{xi}}=\mathrm{C}_{\mathrm{xi}}^{\prime}\left(\overline{\mathrm{v}}_{\mathrm{j}} / \overline{\mathrm{v}}_{\mathrm{j}}^{\prime}\right)^{9 / 5}
$$

and $\overline{\mathrm{v}}_{\mathrm{j}} / \overline{\mathrm{v}}_{\mathrm{j}}{ }_{\mathrm{j}}$ is a large number for fully-developed turbulent pipe flow. For example, taking $\overline{\mathrm{v}}_{\mathrm{j}}{ }^{\prime} / \overline{\mathrm{v}}_{\mathrm{j}}=0.03$ which is a typical value in the bulk liquid for fully-developed turbulent pipe flow from Hinze, ${ }^{25}$ as before, yields $\mathrm{C}_{\mathrm{xi}}^{\prime}=1.8$ which is a number on the order of unity which is expected based on phenomenological analysis considerations. 


\section{Ligament and Drop Properties Along the Liquid Surface}

An expression for the variation of ligament diameter as a function of distance from the jet exit due to effects of turbulent primary breakup was developed following the approach of Sallam and Faeth, ${ }^{21}$ which in turn employed methods from earlier turbulent primary breakup considerations due to $\mathrm{Wu}$ et al. ${ }^{14}$ This approach was adopted after the close relationship between the diameters of ligaments that are just forming drops at a point (the most prominent ligaments at a point due to their length) and the corresponding diameters of drops formed by Rayleigh breakup of these ligaments was noted. This was done with consideration given to the convection of a ligament along the surface of a turbulent liquid jet for the Rayleigh breakup time required to form a full-length ligament that is ready to produce a drop. Weber ${ }^{26}$ showed that the Rayleigh breakup time of a liquid jet having a diameter of $\mathrm{d}_{\mathrm{lig}}$, and thus, a ligament of similar size under present assumptions, is as follows:

$$
\mathrm{t}_{\mathrm{r}} \sim\left(\rho_{\mathrm{L}} \mathrm{d}_{\text {lig }}{ }^{3} / \sigma\right)^{1 / 2}+3 \mu_{\mathrm{L}} \mathrm{d}_{\text {lig }} / \sigma
$$

where the second term on the right-hand side of Eq. (5) accounts for effects of liquid viscosity to increase the Rayleigh breakup time. For present conditions, the viscous term in Eq. (5) is small and can be ignored. Then Eq. (5) becomes:

$$
\mathrm{t}_{\mathrm{r}} \sim\left(\rho_{\mathrm{L}} \mathrm{d}_{\mathrm{lig}}{ }^{3} / \sigma\right)^{1 / 2}
$$

which is independent of the ligament velocity. Then under the assumption that the ligament is simply convected along the liquid surface for the ligament breakup time, the location where a ligament having a particular diameter reaches its full length is given by

$$
\mathrm{x} \sim \overline{\mathrm{v}}_{\mathrm{j}} \mathrm{t}_{\mathrm{r}}
$$

Finally, substituting Eq. (6) into Eq. (7) and normalizing the streamwise distance by the radial integral scale, $\Lambda$, yields the following expression for the variation of $\mathrm{d}_{\text {lig }} / \Lambda$ with distance from the jet exit:

$$
\mathrm{d}_{\mathrm{lig}} / \Lambda=\mathrm{C} \ell_{\mathrm{x}}\left[\mathrm{x} /\left(\Lambda \mathrm{We}_{\mathrm{L \Lambda}}^{1 / 2}\right)\right]^{2 / 3}
$$

where $\mathrm{C}_{\ell}$ is a constant of proportionality that should be on the order of unity. Ligaments of interest here are those that are forming drops at a particular distance from the jet exit; therefore, the ligament diameters increase with increasing distance from the jet exit because larger ligaments require a longer time to develop and break up, as indicated by Eq. (6), and thus, required a larger distance from the jet exit as indicated by Eq. (7).

Present measurements of ligament diameters along the surface of turbulent round liquid jets in still and crossflowing gases are plotted in Fig. 6 , as suggested by Eq. (8). The best-fit correlation of $\mathrm{d}_{\text {lig }} / \Lambda$ according to the variables of Eq. (8), illustrated in Fig. 6, is given by

$$
\mathrm{d}_{\text {lig }} / \Lambda=0.73\left[\mathrm{x} /\left(\Lambda \mathrm{We}_{\mathrm{L \Lambda}}^{\mathrm{l} / 2}\right)\right]^{0.47}
$$

The difference between the best-fit power of Eq. (9), 0.47 , and the theoretical power of Eq. (8), 0.67, is statistically significant but rather modest in view of the approximations of the analysis.

An interesting feature of this result is that crossflow has no effect on the correlation with ligament properties clearly dominated by effects of liquid turbulence. This is not surprising, however, because $\mathrm{Wu}$ and Faeth ${ }^{15}$ found negligible aerodynamic effects on turbulent

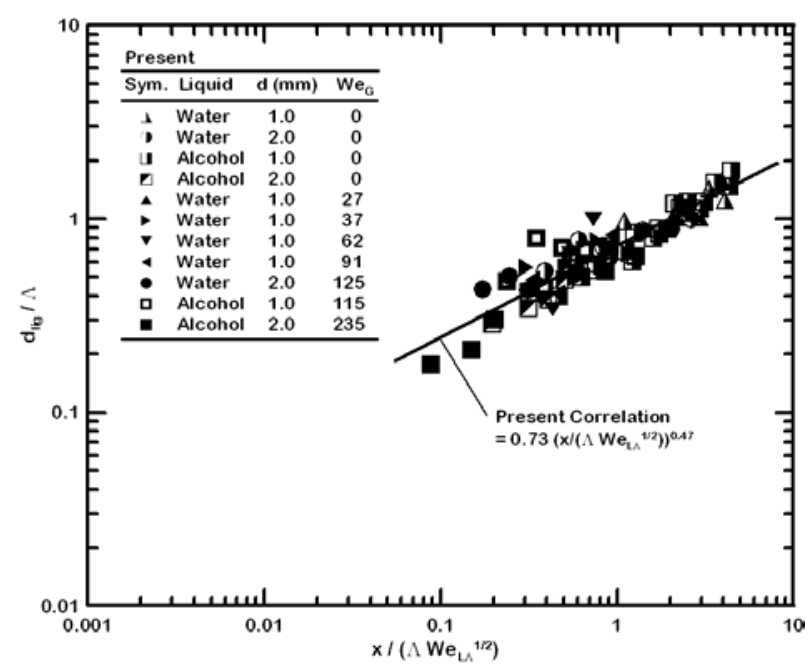

Figure 6. Ligament diameters of round turbulent liquid jets in crossflow as a function of normalized streamwise distance.

8 
primary breakup until $\rho_{\mathrm{L}} / \rho_{\mathrm{G}}<500$ for relative velocities between the gas and liquid phases comparable to the present investigation. Thus, larger cross stream velocities and smaller $\rho_{\mathrm{L}} / \rho_{\mathrm{G}}$ values should be considered to obtain more information about aerodynamic effects near the liquid surface during turbulent primary breakup of round turbulent liquid jets in crossflow.

Earlier study of turbulent primary breakup of round liquid jets in still gases due to Sallam and Faeth ${ }^{21}$ suggested that drop formation at the tip of ligaments involved drop diameters comparable to ligament diameters. Then based on the results of Tyler ${ }^{27}$, this behavior is characteristic of Rayleigh breakup of ligaments and it is reasonable to assume that the SMD of drops formed by ligament breakup are proportional to the corresponding ligament diameter. This implies

$$
\mathrm{SMD} / \Lambda=\mathrm{C}_{\mathrm{s}}\left(\mathrm{d}_{\text {lig }} / \Lambda\right)
$$

where $\mathrm{C}_{\mathrm{s}}$ should be an empirical constant on the order of unity. Then substituting from Eq. $(8)$ for $\left(\mathrm{d}_{\text {lig }} / \Lambda\right)$ there results

$$
\mathrm{SMD} / \Lambda=\mathrm{C}_{\mathrm{s}} \mathrm{C}_{\ell \mathrm{x}}\left[\mathrm{x} /\left(\Lambda \mathrm{We}_{\mathrm{L} \Lambda}^{1 / 2}\right)\right]^{2 / 3}
$$

Present measurements of SMD after turbulent primary breakup along the surface of turbulent round liquid jets in still and crossflowing gases are plotted as suggested by Eq. (11) in Fig. 7. Also plotted on the figure are earlier measurements of drop sizes after turbulent primary breakup in still gases due to Wu and Faeth, ${ }^{15}$ limited to their findings for $\rho_{\mathrm{L}} / \rho_{\mathrm{G}}>500$ similar to the present measurements. The agreement between the results of $\mathrm{Wu}$ and Faeth ${ }^{15}$ and the present investigation is excellent and yields the following combined correlation:

$$
\left.\mathrm{SMD} / \Lambda=0.52\left[\mathrm{x} / \Lambda \mathrm{We}_{\mathrm{L \Lambda}}^{1 / 2}\right)\right]^{0.52}
$$

Notably, the power in Eq. (12), 0.52, is not very different from the theoretical power of Eq. (11), 0.67, whereas the coefficient of Eq. (12) is on the order of unity as expected from a phenomenological theory. These results also support the idea that drop formation for turbulent primary breakup at present conditions occurs by Rayleigh breakup at the tips of ligaments.

Additional measurements of the properties of ligaments were undertaken with the results illustrated in Fig. 8. The first series of results was undertaken for no crossflow and yielded the following relationship between ligament length at the time of breakup and ligament diameter, as follows:

$$
\ell_{\text {lig }} / \mathrm{x}=0.036\left(\mathrm{~d}_{\text {lig }} / \Lambda\right)^{-0.53}, \mathrm{We}_{\mathrm{G}}=0
$$

Subsequent results in the presence of crossflow for the present range of experimental variables;

$$
\ell_{\text {lig }} / \mathrm{x}=0.75\left(\overline{\mathrm{v}}_{\mathrm{j}} / \mathrm{u}_{\infty}\right)\left(\rho_{\mathrm{L}} / \rho_{\mathrm{G}}\right)^{1 / 2}
$$

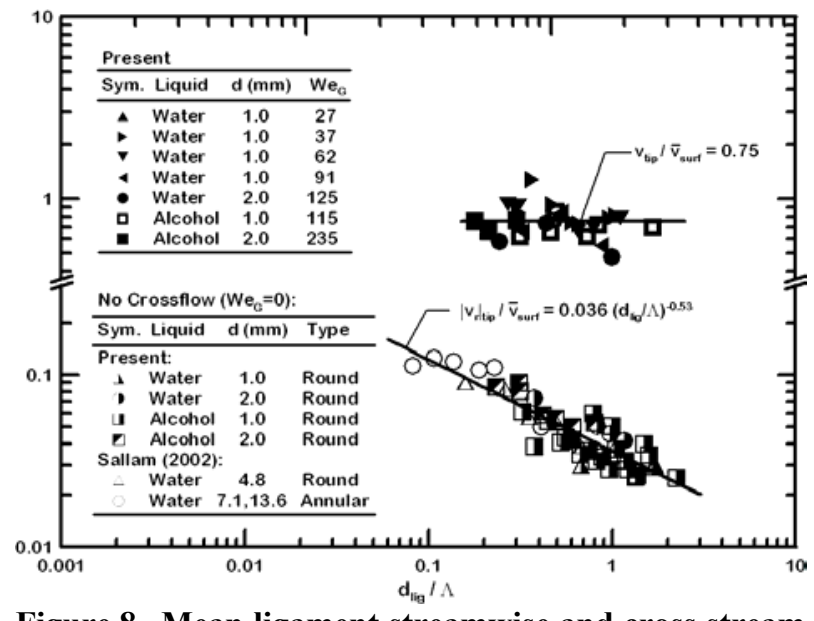

Figure 8. Mean ligament streamwise and cross stream absolute tip velocities for round turbulent liquid jets in still and crossflowing environments. 


\section{Drop Velocities After Turbulent Primary Breakup}

Mean streamwise and cross stream drop velocities after turbulent primary breakup were measured for both still and crossflowing environments. These properties were found to behave similar to drop velocities after breakup of round nonturbulent liquid jets in gaseous crossflows from Sallam et al. ${ }^{2}$ Thus, streamwise drop velocities were proportional to mean streamwise velocities of the liquid:

$$
\overline{\mathrm{v}}_{\mathrm{p}} / \overline{\mathrm{v}}_{\mathrm{j}}=\mathrm{C}_{\mathrm{v}}
$$

whereas, cross stream drop velocities were proportional to the characteristic cross stream velocity of the liquid

$$
\overline{\mathrm{u}}_{\mathrm{p}} / \mathrm{u}_{\mathrm{L}}=\mathrm{C}_{\mathrm{u}}
$$

where

$$
\mathrm{u}_{\mathrm{L}}=\left(\rho_{\mathrm{G}} / \rho_{\mathrm{L}}\right)^{1 / 2} \mathrm{u}_{\infty}
$$

Present measurements of streamwise and cross stream drop velocity distributions are plotted as suggested by Eqs. (15) and (16) in Fig. 9. These results consider both still and crossflowing gases for round fully-developed turbulent liquid jets. First of all, it is clear that drop velocity distributions are uniform similar to other observations of drop velocity distributions after turbulent primary breakup. Best-fit correlations of present measurements of $\bar{v}_{p}$ and $\bar{u}_{p}$ then yield

$$
\overline{\mathrm{v}}_{\mathrm{p}} / \overline{\mathrm{v}}_{\mathrm{j}}=\mathrm{C}_{\mathrm{v}}=0.6
$$

and

$$
\overline{\mathrm{u}}_{\mathrm{p}} / \mathrm{u}_{\mathrm{L}}=\overline{\mathrm{u}}_{\mathrm{p}} /\left(\left(\rho_{\mathrm{G}} / \rho_{\mathrm{L}}\right)^{1 / 2} \mathrm{u}_{\infty}\right)=\mathrm{C}_{\mathrm{u}}=4.27
$$

These results are remarkably similar to findings for primary breakup of nonturbulent round liquid jets in crossflow where Sallam et al. ${ }^{2}$ find $\mathrm{C}_{\mathrm{v}}=0.7$ and $\mathrm{C}_{\mathrm{u}}=$ 6.7. This suggests that the ambient gas, whether still or crossflow, exerts a significant effect on drop velocities after primary breakup along both nonturbulent and turbulent liquid surfaces.

\section{Liquid Breakup Rates due to Turbulent Primary Breakup}

The last liquid surface property that was studied during the present investigation was the flux of liquid drops relative to the liquid surface due to turbulent primary breakup along the liquid surface. The evidence of relatively strong effects of crossflow on drop velocities after turbulent primary breakup suggested that this would best be done using the approach of Sallam et $\mathrm{al}^{2}$ for nonturbulent primary breakup in

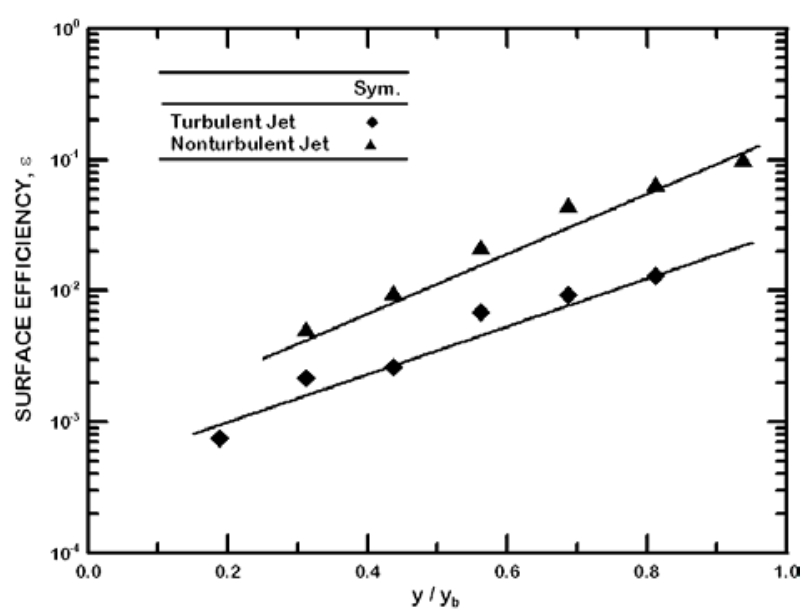

Figure 10. Mean surface efficiency factors as functions of normalized streamwise distance for round turbulent jets in crossflow. 
crossflow. With this approach drops formed by primary breakup are assumed to leave the liquid column over its downstream half, as opposed to the entire periphery which was the approach used for breakup of turbulent liquid jets in still gases. Thus, averaging the liquid removal rate over this downstream projected area to find the average mass flux of liquid drops leaving the liquid column, $\dot{\mathrm{m}}_{\mathrm{L}}{ }^{\prime}$, the liquid surface breakup efficiency factor, $\varepsilon$, is defined as follows:

$$
\varepsilon=\dot{\mathrm{m}}_{\mathrm{L}}{ }^{\prime} /\left(\rho_{\mathrm{L}} \overline{\mathrm{u}}_{\mathrm{p}}\right)
$$

where the limit $\varepsilon=1$ represents conditions where liquid drops form in a continuous manner over all the downstream projected area of the liquid.

Present measurements of $\varepsilon$ for primary breakup of turbulent round liquid jets in crossflowing air are illustrated in Fig. 10. The independent variable used in this plot is the dimensionless streamwise length, $y / y_{b}$, between the jet exit and the condition where the liquid jet breaks up as a whole. Typical of the earlier measurements of Sallam et al. ${ }^{2}$ for breakup of nonturbulent round liquid jets in gaseous crossflows, values of $\varepsilon$ are small at the onset of breakup but increase toward unity as the end of the liquid column is approached in a relatively universal manner.

\section{CONCLUSIONS}

This investigation considered the formation of ligaments and drops along the surface of a round turbulent liquid jet in air crossflows at normal temperature and pressure. Test conditions included water and ethyl alcohol jets with fully-developed turbulent pipe flow properties injected normal to the crossflow for the following ranges of test variables: crossflow Weber numbers based on gas properties of 0-282, streamwise Weber numbers based on liquid properties of 5,100-24,500, liquid/gas density ratios of 683 and 845, liquid jet exit Reynolds numbers of 3,80059,000 , and Ohnesorge numbers less than 0.12 . The major conclusions of the study were as follows:

1) Streamwise mean liquid jet surface velocities varied to a negligible degree in the streamwise direction and approximated mean liquid velocities at the injector exit, suggesting that effects of streamwise gas drag on the liquid jet were small.

2) The onset of turbulent primary breakup always occurred at some distance from the jet exit but approached the exit, approximating atomization breakup conditions, at large $\mathrm{We}_{\mathrm{L} \Lambda}$.

3) Ligament and drop diameters due to turbulent primary breakup increased with increasing distance from the jet exit, with these diameters becoming comparable to the radial integral scale of the liquid turbulence as the end of the liquid column is approached.

4) The correlation between drop SMD and streamwise distance along the liquid jet was not affected by the crossflow, suggesting that turbulent primary breakup dominates aerodynamic effects for present test conditions near the liquid surface. Similar to ligament and drop diameters, the SMD was comparable to the radial integral scale of the liquid turbulence as the end of the liquid column was approached.

5) Drop velocities after turbulent primary breakup in crossflow were independent of drop size with streamwise drop velocities comparable to mean streamwise liquid velocities and cross stream drop velocities somewhat larger than the characteristic velocity of the liquid jet in the cross stream direction, which is behavior very similar to drop velocities after primary breakup of nonturbulent round liquid jets in crossflow.

6) The mean drop mass flux over the downstream projected area of the liquid column due to turbulent primary breakup at the liquid surface could be correlated by a surface efficiency factor that was small at the onset of breakup but increased to a value near unity as the end of the liquid column was approached.

\section{ACKNOWLEDGMENTS}

This research was sponsored by the U.S. Air Force Office of Scientific Research, Grant Nos. F49620-99-1-0083, F49620-02-1-0007 and FA9550-05-1-0009 under the Technical Management of J.M. Tishkoff. Assistance from R. 
Jolly and D. Ma under the University of Michigan Undergraduate Research Opportunity Program is gratefully acknowledged.]

\section{REFERENCES}

${ }^{1}$ Mazallon, J., Dai, Z., and Faeth, G.M., "Primary Breakup of Nonturbulent Round Liquid Jets in Gas Crossflows," Atomization and Sprays Vol. 9, No. 3, 1999, pp. 291-311.

${ }^{2}$ Sallam, K.A., Aalburg, C., and Faeth, G.M., "Breakup of Round Nonturbulent Liquid Jets in Gaseous Crossflow," AIAA Journal (in press).

${ }^{3}$ Aalburg, C., van Leer, B., Faeth, G. M., and Sallam, K.A., "Properties of Nonturbulent Round Liquid Jets in Uniform Gaseous Crossflows," Atomization and Sprays, in press.

${ }^{4}$ De Juhasz, K.J., Zahn, O.F., Jr., and Schweitzer, P.H., “On the Formation and Dispersion of Oil Sprays,” Bulletin No. 40, Engineering Experimental Station, Pennsylvania State University, University Park, PA, 1932.

${ }^{5}$ Lee, D.W., and Spencer, R.C., "Preliminary Photomicrographic Studies of Fuel Sprays," NACA Report No. 424, Washington, D.C., 1933.

${ }^{6}$ Lee, D.W., and Spencer, R.C., "Photomicrographic Studies of Fuel Sprays," NACA Report No. 454, Washington, D.C., 1933.

${ }^{7}$ Schweitzer, P.H., "Mechanism of Disintegration of Liquid Jets,” Journal of Applied Physics, Vol. 8, 1937, pp. 513-521.

${ }^{8}$ Chen, T.-F., and Davis, J.R., "Disintegration of a Turbulent Water Jet," Journal of the Hydraulic Division, Vol. 1, 1964, pp. 175-206.

${ }^{9}$ Grant, R.P., and Middleman, S., "Newtonian Jet Stability,” AIChE Journal, Vol. 12, 1966, pp. 669-678.

${ }^{10}$ Phinney, R.E., "The Breakup of a Turbulent Jet in a Gaseous Atmosphere," Journal of Fluid Mechanics, Vol. 60, 1973, pp. 689-701.

${ }^{11}$ McCarthy, M.J., and Malloy, N.A., "Review of Stability of Liquid Jets and the Influence of Nozzle Design," Chemical Engineering Journal, Vol. 7, 1974, pp. 1-20.

${ }^{12}$ Hoyt, J.W., and Taylor, J.J., "Waves on Water Jets," Journal of Fluid Mechanics, Vol. 88, 1977, pp. 119-123.

${ }^{13}$ Hoyt, J.W., and Taylor, J.J., "Turbulence Structure in a Water Jet Discharging in Air,” Physics of Fluids, Vol. 20, 1977, pp. S253-S257.

${ }^{14}$ Wu, P.-K., Tseng, L.-K., and Faeth, G.M., "Primary Breakup in Gas/Liquid Mixing Layers for Turbulent Liquids," Atomization and Sprays, Vol. 2, 1992, pp. 295-317.

${ }^{15}$ Wu, P.-K., and Faeth, G.M., "Aerodynamic Effects on Primary Breakup of Turbulent Liquids," Atomization and Sprays, Vol. 3, No. 3, 1993, pp. 265-289.

${ }^{16}$ Wu, P.-K., Miranda, R.F., and Faeth, G.M., "Effects of Initial Flow Conditions on Primary Breakup of Nonturbulent and Turbulent Round Liquid Jets," Atomization and Sprays, Vol. 5, No. 2, 1995, pp. 175-196.

${ }^{17}$ Wu, P.-K., and Faeth, G.M., "Onset and End of Drop Formation Along the Surface of Turbulent Liquid Jets in Still Gases," Physics of Fluids A, Vol. 7, No. 11, 1995, pp. 2915-2917.

${ }^{18}$ Dai, Z., Chou, W.-H., and Faeth, G.M., "Drop Formation Due to Turbulent Primary Breakup at the Free Surface of Plane Liquid Wall Jets," Physics of Fluids, Vol. 10, No. 5, pp. 1998, pp. 1147-1157.

${ }^{19}$ Sallam, K.A., Dai, Z., and Faeth, G.M., "Drop Formation at the Surface of Plane Turbulent Liquid Jets in Still Gases," International Journal of Multiphase Flow, Vol. 25, 1999, pp. 1161-1180.

${ }^{20}$ Sallam, K.A., Dai, Z., and Faeth, G.M., "Liquid Breakup at the Surface of Turbulent Round Liquid Jets in Still Gases," International Journal of Multiphase Flow, Vol. 28, No. 3, 2002, pp. 427-449.

${ }^{21}$ Sallam, K.A., and Faeth, G.M., "Surface Properties During Primary Breakup of Turbulent Liquid Jets in Still Air," AIAA Journal, Vol. 41, No. 8, 2003, pp. 1514-1524.

${ }^{22}$ Simmons, H.C., "The Correlation of Drop-Size Distributions in Fuel Nozzle Sprays," Journal of Engineering for Power, Vol. 99, No. 3, 1977, pp. 309-319.

${ }^{23}$ Schlichting, H., Boundary Layer Theory, 4th ed., McGraw-Hill, New York, 1960, pp. 72-73 and 599.

${ }^{24}$ Lange, N.A. Handbook of Chemistry, 8th ed., Handbook Publishers, Inc., Sandusky, Ohio, 1984, pp. 13-17.

${ }^{25}$ Hinze, J.O., Turbulence, 2nd ed., , McGraw-Hill, New York, 1975, pp. 724-742.

${ }^{26}$ Weber, C., "Zum Zerfall eines Flussigkeitsstrahles," Zeitschrift Angewesen Mathematik and Mechanik, Vol. 2, 1931, pp. 136-141.

${ }^{27}$ Tyler, E., “Instability of Liquid Jets,” Philosophical Magazine, Vol. 16, 1933, pp. 504-518. 